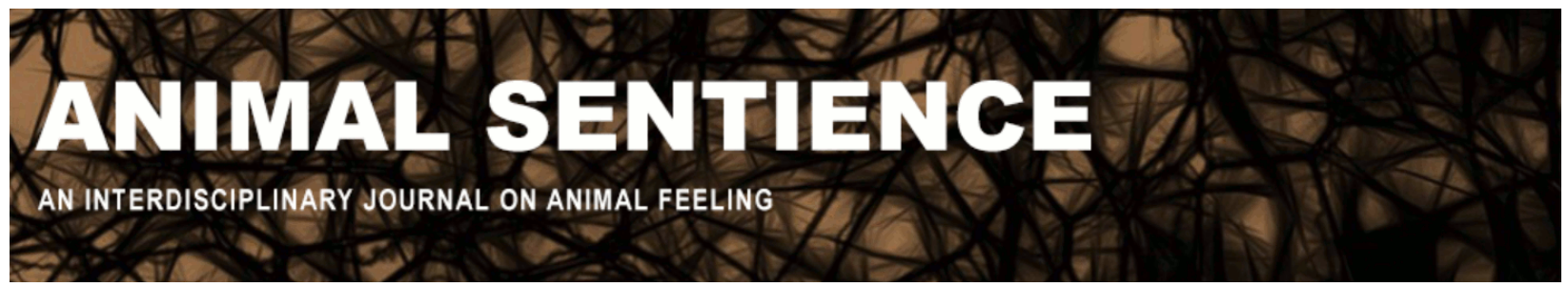

Broude, Gwen J. (2016) Who is a person? Whoever you want it to be. Animal Sentience 10(5)

DOI: $10.51291 / 2377-7478.1132$

Date of submission: 2016-08-03

Date of acceptance: 2016-08-09

(c)

This article has appeared in the journal Animal

Sentience, a peer-reviewed journal on animal

cognition and feeling. It has been made open access,

free for all, by WellBeing International and deposited

in the WBI Studies Repository. For more information,

please contact

wbisr-info@wellbeingintl.org.

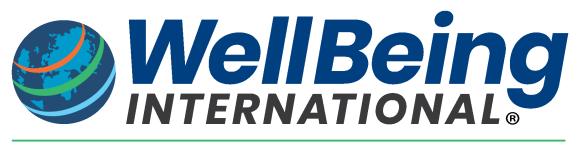

SOLUTIONS FOR PEOPLE, ANIMALS AND ENVIRONMENT 


\title{
Who is a person? Whoever you want it to be
}

Commentary on Rowlands on Animal Personhood

\author{
Gwen J. Broude \\ Cognitive Science \\ Vassar College, Poughkeepsie, New York
}

\begin{abstract}
Rowlands provides an expanded definition of personhood that preserves the requirement of unity of mental life from the orthodox definition but argues that implicit unity of mind is sufficient for conferring personhood. This allows more or all animals to be considered persons. Implicit unity of mind may be a bridge too far for those who endorse the orthodox account of personhood, and for good reasons. More fundamentally, who gets to decide what personhood entails or that personhood per se matters to such other issues as who receives legal or moral status and consideration? Perhaps we should worry less about definitions of personhood and more about whether and why (all) animals deserve certain kinds of treatment by human animals.
\end{abstract}

Keywords: personhood, moral status, unity of mental life, implicit self-awareness, animal awareness

Gwen J. Broude is Professor of Cognitive Science at Vassar College. Her research interests include the application of crosscultural and evolutionary theory to human mind and behavior. She also has an interest in phenomenological approaches to mind. https://cogsci.vassar.edu/bios/broude.html

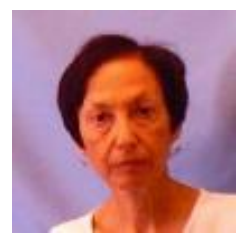

In his target article, Are animals persons?, Mark Rowlands (2016) is exploring two issues related to personhood. His ostensible focus is on the question of whether animals are persons, as is indicated by his choice of title. This requires, however, a prior commitment to the meaning of personhood itself, as Rowlands indicates in his introduction. Thus, Rowlands is treating two metaphysical questions, where metaphysical means "pertaining to what something is." He is asking what kind of thing is a person and what animals are the kinds of things that we should call persons.

But how do these questions concerning personhood come to be addressed? Why ask such questions? Why care what a person is and who gets to be a person? Why define personhood one way as opposed to another? And, who gets to decide the answer to that metaphysical question?

Let's begin with Rowlands's strategy for working out who should be identified as a person. The article accepts the orthodox definition of personhood as given. Thus, personhood is achieved when there is (1) a mental life, and (2) unity (of that mental life). Unity of mind is achieved when 
an agent can "consider itself [to be] the same thinking thing, in different times and places." The agent appreciates that all of its mental states and processes are its own. Yet while accepting this orthodox definition of personhood Rowlands wants to persuade the reader to adopt an expanded interpretation of what counts as unity of mental life. Conventionally, unity of mind requires reflective or explicit self-awareness. But, based upon logical and phenomenological arguments, Rowlands argues that agents are necessarily already endowed with such unity before explicit self-awareness kicks in. Thus, even accepting the orthodox definition of personhood, many more (perhaps all) animals are persons than is standardly acknowledged.

How should we respond to the case that Rowlands presents?

The argument for an expanded understanding of what constitutes unity of mental life is based on the idea that such unity of mind is grounded in something called pre-reflective selfawareness: so too is reflective self-awareness. Pre-reflective self-awareness is thus prior to and necessary for the standard condition for unity of mental life and is itself good enough for mental unity.

We can evaluate this claim per se, and I do want to comment selectively on the argument from Rowlands, which is consistent with phenomenological accounts of mind and life. But there are also prior questions to be addressed, and I will return to those later.

So, what should we make of Rowlands's case for an expanded conception of unity of mental life? The orthodox view of what it takes to achieve such mental unity depends upon the idea of explicit self-consciousness. I have the capacity to be explicitly aware of myself as a thinking thing (although I am not always monitoring myself in this way). I can take myself and my mental life as objects to be thought about. This is the meta-cognition to which Rowlands alludes. If I have language, I can also say to you, for instance, or to myself: "I am the thing that was just thinking about X." This is what "reflective" refers to in reflective self-awareness. Reflective implies explicitness.

By contrast, Rowlands introduces a second version of unity, which he identifies as implicit selfawareness. With implicit self-awareness, there is no requirement of explicit awareness of myself as a potential object of my own thought, an object to be thought about by me. Indeed, Rowlands continues, unity of mental life is not separate from life itself; it is not something to be added on later or separately. There is a kind of mental life that already has its own unity before self-consciousness emerges and it is made up of what Rowlands calls experiencing as. Seeing, for example, a book as a book, or a chair as a chair is experiencing as. Whenever we find this process, says Rowlands, we find unity of mental life and we have a person.

Is it reasonable to claim that animals without explicit self-awareness have some kind of unified mental life? Sure. Here are some other reasons for why one might come to believe that many, maybe all, animals have some kind of unity of mind, some variety of being "the same thinking thing, in different times and places." If you are an organism, it seems to follow that you somehow know where you end and the rest of the world begins (Harper 1989). In that case, 
there would be some kind of stable "knowledge" of "you" versus "not you." This is consistent with the observation that animals of all sorts avoid doing harm to themselves except under extreme conditions but are willing to do harm to others. Preserving one's own bodily integrity seems to require some kind of awareness of what counts as one's body. Even sacrificing part of one's body can suggest knowledge of where your body begins and ends. Foxes whose paw and lower leg are caught in a rabbit trap have been observed gnawing on the leg clear through the bone, thus freeing themselves. The action implies an appreciation of some sort on the part of the fox that the leg imprisoned in the trap belongs to him (Denton 2005). A final example: even for a very simple organism, relevant objects and events in the world would need to have stable meaning as "good for me" and "bad for me" - implicitly (Cisek 1999). These all sound like indications of sameness of self, of evaluations, and hence of mental life in different times and places.

If there is a problem with Rowlands's expanded version of unity of mental life, it is with the idea of implicitness. Implicit and explicit are not the same thing. The idea of implicitness - implicit knowledge, implicit competence, and so on - shows up quite a lot in discussions of mind and behavior. One example: a young child who will not make a particular grammatical error in his own speech - for instance, he will not say "Car the drive" instead of "Drive the car" - cannot say whether a hand puppet is making a mistake when it says "Car the drive." The child seems to know something about grammar since he avoids grammatical errors in his own speech. But something is missing. He cannot judge the grammaticality of language more generally and he certainly does not know the rule regarding where subjects and objects go in a sentence. Psychologists say that the child has implicit knowledge of grammar. The child knows something but something is lacking - explicit knowledge of grammar (Ellis 2008). The same kind of claim is made about numbers, laws of physics, and so on with respect both to children and to other animals.

Those who promote the orthodox view of what it takes to have unity of mental life think that there is a difference between implicit and explicit self-reflectiveness that is not trivial. Hence, explicit is different enough from implicit to be the kind of difference useful in judging presence or absence of personhood.

Rowlands's claim that experiencing as is a foundational capacity of most (all?) animals also rests on the idea of implicitness. His claim is that animals who do not have explicit self-awareness nevertheless implicitly experience things as this or as that - as a book, as a chair. My dog experiences a bone as a bone. And personhood extends into the animal realm whenever there is experiencing as.

Does my dog experience a bone as a bone, though? It depends upon what the meaning of "as" is. And to whom $X$ is experienced as $X$. When I perceive a bone as a bone, I am exploiting my prior abilities to form and recognize concepts and categories. I can explicitly list features of items belonging to the category of book, chair, and bone, for instance. My dog cannot, I think. My dog has a practical relationship with bones - the affordances to which Rowlands alludes. He knows what they are good for from his point of view. He experiences a bone pragmatically as 
something he can gnaw on. Is this the same as explicitly experiencing a steak bone as a member of the category "bone," itself identified by a set of features? Promoters of orthodox views regarding unity of mental life would insist that implicit versus explicit categorization are importantly different. In reality, the book is experienced as a book, the chair as a chair by Rowlands, who then seems to be exporting that ability to other animals through the back door for free. Borrowing from Raymond Tallis (2004), the ability to explicitly categorize, to attach labels to objects and categories, means that an object is never just located in a particular place at a particular time. Because we human beings have labels for things and categories, whenever we experience any specific object, we simultaneously experience it as an instance of the general kind - the category. This is not implicit. For Tallis this is one difference between sentience and explicit self-awareness. I cannot prove that my dog does not experience the bone that he is enjoying right now as a member of the category "bone" with a set of defining features. But I would be surprised if it were true.

To conclude, implicit versus explicit is a difference that makes a difference for some, and enough of a difference to mean that implicit unity of mind does not make a person. The idea of implicit knowledge, cognition, competence, and the rest, used promiscuously, turns into a monstrous black hole that sucks up and homogenizes every kind of mental state and process into one amorphous bundle. This is not an endorsement from me of the orthodox view of personhood. It is a worry about the conflation of implicit and explicit.

Does our ultimate evaluation of Rowlands's argument influence our decision about whether animals are persons? Here we come to issues prior to the question about animal personhood posed by Rowlands. Specifically, why ask whether animals are persons in the first place? Why care? And - who gets to decide what is constitutive of a person anyhow?

Last question first: who gets to decide about personhood's defining features? I said at the beginning of this commentary that Rowlands is ostensibly exploring the question of whether animals are persons. In reality, he has redefined personhood - implicitly. Maybe the redefinition is also ostensible, however, since it respects the original commitment of unity of mental life as part of the orthodox definition of personhood. But here is a (for me) more fundamental question: how would we know who is right or wrong about what constitutes personhood? Is the category "personhood" some kind of revelation from above? Is there some carving of nature at its joints such that there is an objective personhood with foreordained orthodox membership criteria? Or with some other membership criteria?

This takes us to the issue of what definitions are and do. Henry Plotkin (1997) views definitions as a kind of propaganda, a way of broadcasting one's theoretical commitments. Different commitments, different definitions. Hence, perhaps, the difference between Rowlands and the orthodox position on the nature of personhood. Each derives from a specific and different prior theoretical commitment.

What propaganda would lie behind different definitions of personhood? Rowlands remarks that the orthodox definition happens to omit all or most other animals from personhood. Human 
beings are persons, other animals are not (or, lately, mostly are not). This reminds me of the shifting definitions of humanness that I was required to learn in my anthropology classes over the years. Thus, human beings but no other animals were tool-users, then tool-makers, then language-users, then culture-bearers, and nowadays, explicitly self-reflective, hence, persons. The target shifts as we become more informed about the capacities of other animals. The propaganda here looks like an attempt to find yet another criterion that separates human beings from other animals. First comes the desire for an airtight case that we are unique, the theoretical commitment. Then comes the search for some definition that will make the case. And so it may be with personhood.

Why would anyone want to do that?

While Rowlands limits himself to the metaphysical question of whether animals are persons, he recognizes that questions of personhood are also relevant to legal and moral concerns. A person is seen by some as the sort of thing to which legal and/or moral status or consideration is owed. So why do we ask whether animals are persons and why care? Perhaps at least partly because the answer has actual legal and moral implications out here in the world as long as personhood is considered a criterion for legal and/or moral consideration. An orthodox definition narrows the range of species to which legal and/or moral consideration is owed. A more expansive definition expands the range of candidates who might enjoy such status and consideration. Rowlands is, I assume, sympathetic to this second alternative. Hence the broader definition of person. We could conjecture that Rowlands is redefining person so that every animal gets to be one.

Who cares about who is a person or what is constitutive of a person? Orthodox personhood is (at least for some thinkers) basically a proxy-label for features that until recently looked promising as separating human beings from other animals and therefore allowing members of the two categories - persons and non-persons - to be thought about and treated differently. This, incidentally, is the fourth concern (the others being legal, moral, and metaphysical) that motivates questions about personhood - the concern to find a difference between human and other animals that might, finally, stick.

Here is a last question: why should personhood, defined in whatever way, be the litmus test for legal/moral status or consideration? Discussion of how to define a person per se can actually become a distraction from the conversation about what kind of entity deserves certain legal and moral status and consideration and why. Rowlands himself understands and explicitly comments on the way that definitions of personhood are motivated by a desire to differentiate between human beings and other animals. At the end of his article, he observes: "... instead of thinking of all the ways in which animals might not be persons, or juggling with one's conception of a person to ensure that animals are disqualified, it might be more fruitful instead to think of the ways in which they are." But, why not just reject the idea that personhood is the right measure of status and consideration altogether. Let's find other standards. 
Disengaged, however, from the question of who is a person, which is for me a red herring, Rowlands's phenomenological narration of animal experience and awareness is exactly the kind of thing that we need more of. Such descriptions, stripped of contentious superordinate labels such as personhood and illuminating the experience of other animals, may persuade more of us to see the lives of other animals as deserving of respect.

\section{References}

Cisek, P. (1999). Beyond the computer metaphor: Behavior as interaction. Journal of Consciousness Studies, 6(11-12), 125-142.

Denton, D. (2005). The Primordial Emotions: The Dawning of Consciousness. New York: Oxford University Press.

Ellis, N. (2007). Implicit and explicit knowledge about language. In J. Cenoz \& N. H. Hornberger (Eds.), Encyclopedia of Language and Education, 2nd Edition, Volume 6: Knowledge about Language (pp. 119-132). New York: Springer Publishing.

Harper, L. (1989). The Nurture of Human Behavior: The Biopsychology of Human Behavioral Development. New York: Ablex Publishing.

Plotkin, H. (1997). Darwin Machines and the Nature of Knowledge. Cambridge, MA: Harvard University Press.

Rowlands, M. (2016). Are animals persons? Animal Sentience 2016.101.

Tallis, R. (2004). The Knowing Animal: A Philosophical Inquiry into Knowledge and Truth. Edinburgh, UK: Edinburgh University Press. 